\title{
ESTADO ACTUAL DEL DIAGNÓSTICO Y TRATAMIENTO DEL TUMOR TESTICULAR DE CÉLULAS DE LEYDIG. APORTACIÓN DE DOS CASOS
}

Héctor Pastor Navarro, María J. Donate Moreno, Pedro Carrión López, José M. Pastor Guzmán, Miguel Segura Martín, María M. Lorido Cortés', Luis Cañamares Pabolaza, Rafael Ruíz Mondéjar, Antonio S. Salinas Sánchez y Julio A. Virseda Rodríguez.

Servicio de Urología. Servicio de Anatomía Patológica'. Complejo Hospitalario Universitario de Albacete. Albacete. España.

Resumen.- OBJETIVO: Revisar el diagnóstico y tratamiento actual de los tumores testiculares de células de Leydig, poniendo especial atención en el tratamiento conservador.

MÉTODOS: Presentamos dos casos de tumor de células de Leydig en adultos jóvenes, diagnosticados dos años después de aparecer ginecomastia bilateral como primera manifestación clínica.

RESULTADOS: al año y ocho meses respectivamente de efectuarse la orquiectomía, las manifestaciones clínicas desaparecieron totalmente en el primer caso y mejoraron ostensiblemente en el segundo.
Héctor Pastor Navarro

San Antonio, 47 - 4 D

02001 Albacete. (España).

hektorpn@hotmail.com

Trabajo recibido: 4 de mayo 2007
CONCLUSIONES: Alrededor del 10\% y sólo en adultos, estos tumores pueden ser malignos, siendo el tratamiento de elección la orquiectomía radical, aunque es posible la realización de cirugía conservadora. El seguimiento de estos pacientes, independientemente de la cirugía practicada, debe ser prolongado.

Palabras clave: Tumor testicular. Tumor de células de Leydig. Ginecomastia. Hormonas.

Summary.- OBJECTIVES: To review the current diagnosis and treatment of Leydig cell testicular tumors, with special attention to conservative treatment.

METHODS: We report two cases of Leydig cell tumor in young adults, diagnosed two years after the appearance of bilateral gynecomastia as first clinical symptom.

RESULTS: One year and eight months after orchyectomy, respectively, clinical symptoms completely disappear in the first case and significantly improved in the second.

CONCLUSIONS: Around 10\% of the cases, and only in adult patients, these tumors may be malignant, being radical orchyectomy the treatment of choice, although conservative surgery may be performed. Independently of the operation, follow-up must be prolonged.

Keywords: Testicular tumor. Leydig cell tumor. Gynecomastia. Hormones. 


\section{INTRODUCCIÓN}

Los tumores testiculares representan el $1 \%$ de las neoplasias malignas del varón, y son la causa mas común de tumor maligno entre los 15 y los 35 años; la mayoría derivan de las células germinales $(93 \%)$ y el restante $7 \%$ de las células del estroma gonadal (células de Leydig, células de Sertoli y tejido de sostén de las células germinales). Los tumores de células de Leydig suponen el 1-3\% del total de todos los tumores testiculares.

Es el más común de los tumores testiculares de células no germinales. Su origen deriva de las células intersticiales del testículo (1-3). En 1895 Sacchi describió en un niño el primer caso de tumor de células de Leydig (4). La primera reseña bibliográfica de un estudio exhaustivo de la histopatología de los TCL se debe a Cervos Navarro en $1964(5,6)$. Se ha diagnosticado en todas las edades, pero presenta dos picos de máxima incidencia, en niños prepúberes y en adultos en la $3^{3}-4^{a}$ década de la vida (1).

La bilateralidad en los tumores testiculares es excepcional, sólo ocurre en el 0,7\% sincrónicamente, y con carácter metacrónico (hasta en los 5 años posteriores al diagnóstico del contralateral) en el 1,5\%. Sin embargo en los tumores de Leydig y Sertoli puede elevarse al $5-10 \%$.

Presentamos dos casos de tumor testicular de células de Leydg en dos adultos jóvenes, diagnosticados dos años después de aparecer ginecomastia bilateral, como primera manifestación clínica.

\section{CASOS CLÍNICOS}

\section{Caso clínico 1.}

Paciente de 26 años con antecedente de enfermedad de Perthes en cadera derecha, que consultó hace dos años a su médico por aumento de tamaño y dolor en mama derecha. El paciente se perdió para controles durante un año y medio, siendo remitido entonces a la consulta de endocrinología, por ginecomastia y dolor mamario bilateral, acompañándose de ligera disminución del apetito sexual. A la exploración se confirmó la existencia de ginecomastia bilateral de predominio derecho.

En estudio analítico repetido en tres ocasiones se comprobó la normalidad de marcadores tumorales en los que se incluyó alfafetoproteina y beta-HCG. El estudio hormonal fue normal para prolactina, FSH, LH, testosterona y DHEA; sólo el estradiol en tres determinaciones estaba en rangos por encima de la normalidad 157,59 y $62 \mathrm{pg} / \mathrm{mL}$. - normal en varones entre 11-44 pg/mL). En mamografía y ecografía mamaria se confirma la proliferación de tejido fibroglandular en ambas regiones retroareolares, de aspecto arboriforme en mama derecha y más nodular en mama izquierda, hallazgos compatibles con ginecomastia bilateral asimétrica de predominio derecho.

El servicio de endocrinología solicitó ecografía testicular aunque a la exploración ambos testes no mostraban patología ni se palparon nódulos. En la ecografía testicular en el testículo derecho existía imagen de masa sólida hipoecogénica de 1,15 x

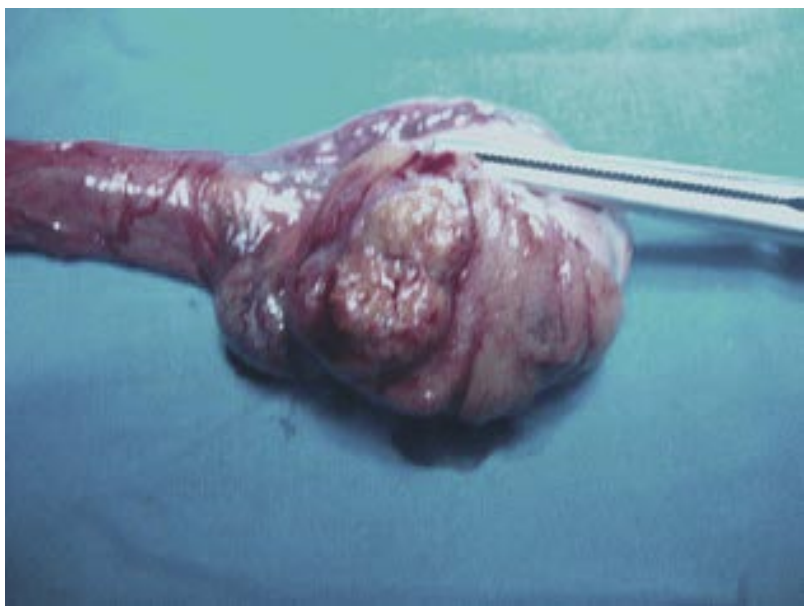

FIGURA 2. Pieza de orquiectomía con tumoración testicular bien delimitada.

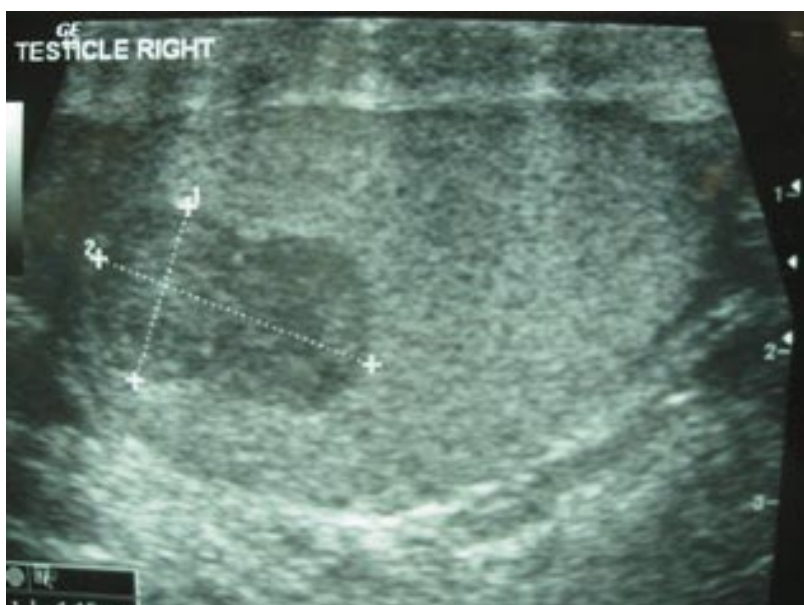

FIGURA 1. Ecografía testicular con nódulo hipoecoico. 


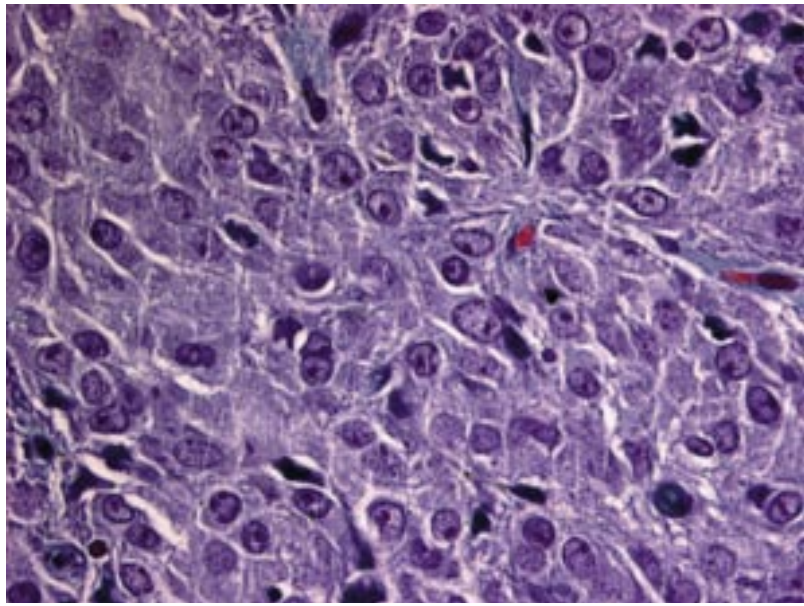

FIGURA 3. Células tumorales mostrando abundante citoplasma, núcleos redondeados y nucleolos prominentes. (Tricrómico de Masson).

$1,85 \mathrm{~cm}$ (Figura 1), con contorno externo bilobulado, con contenido interno del mismo algo heterogéneo, alternando zonas mas hipoecogénicas con otras más ecógenas bien vascularizadas. Testículo izquierdo normal. El estudio de extensión mediante TAC toracoabdominopélvico fue normal.

Con la presunción de que podía tratarse de tumor testicular productor de hormonas, tipo células de Sertóli o Leydig, se efectúo orquiectomía radical, llamando la atención de que el tumor no era palpable ni siquiera en la pieza de orquiectomía. A la apertura de la albugínea se aprecia una tumoración muy bien delimitada del parénquima testicular sano (Figura 2).

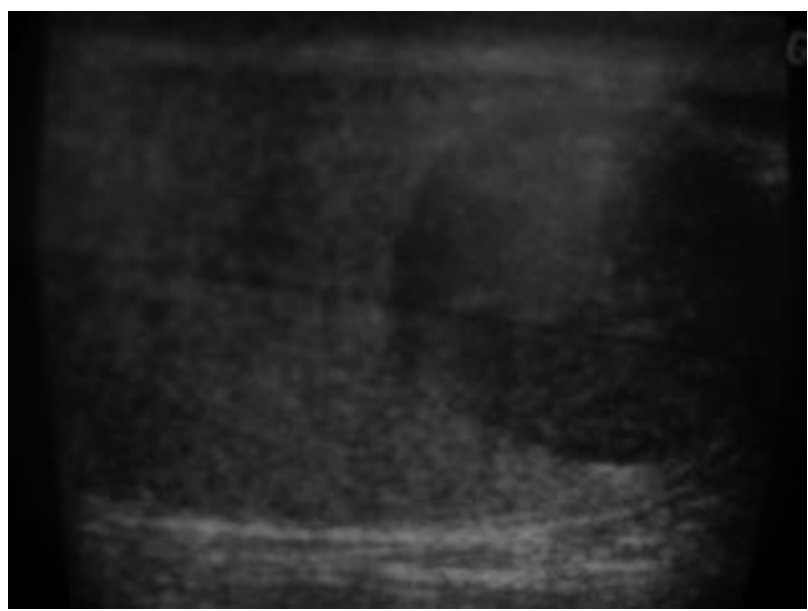

FIGURA 5. Ecografía testicular con masa hipoecoica bien delimitada.

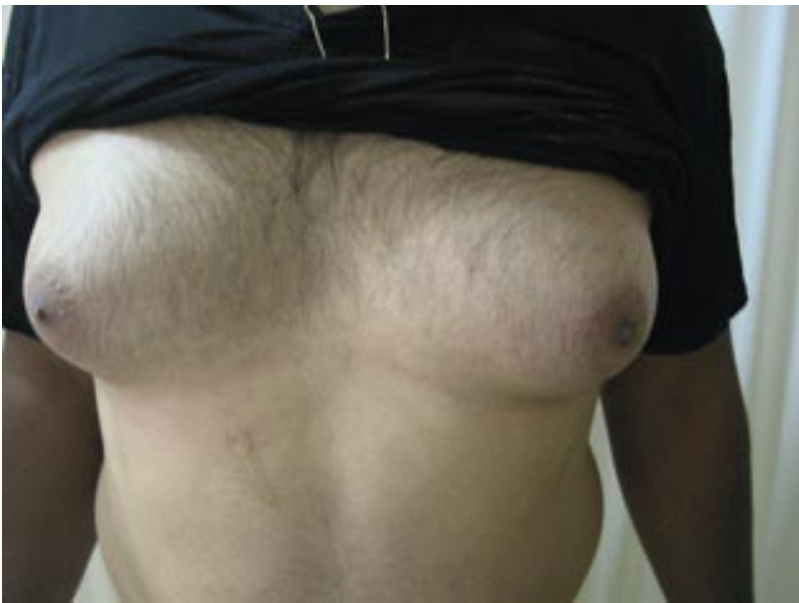

FIGURA 4. Ginecomastia bilateral.

En el estudio histológico de la tumoración se observaron células de citoplasma abundante, eosinófilo o vacuolado, con núcleos redondeados con nucleolo prominente central, que crecen con patrón sólido y a veces muestran lipofuchina citoplasmática o estructuras que sugieren cristaloides de Reinke. La neoplasia estaba limitada al testículo y mostró escasa actividad mitótica; los bordes quirúrgicos, cubiertas testiculares, epidídimo y cordón están libres (Figura 3). El diagnóstico fue de fumor testicular de células de Leydig (TCL).

Un año después de la intervención los estudios hormonales, incluidos los estrógenos plasmáticos son normales. La ginecomastia regresó comple-

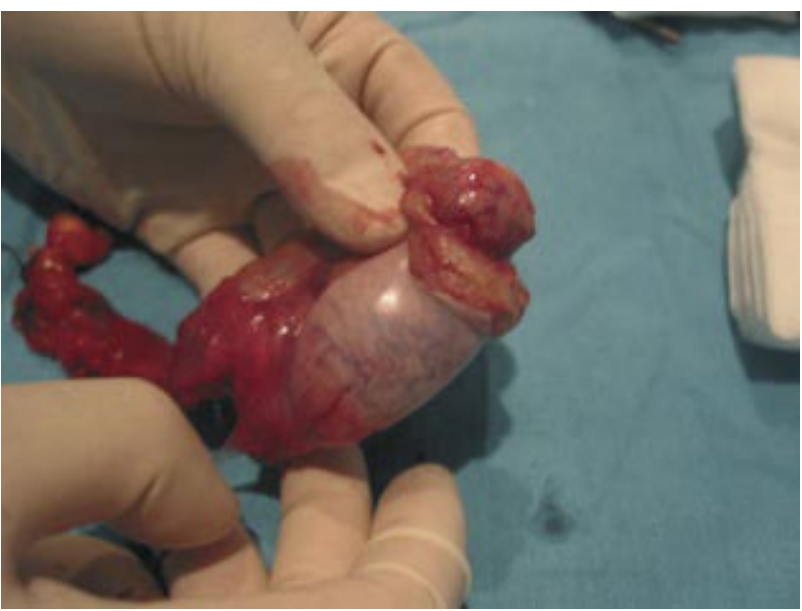

FIGURA 6. Pieza de orquiectomía mostrando tumoración capsulada. 
tamente. No se efectuó espermiograma previo a la orquiectomía, y tampoco permitió que se realizará posteriormente.

\section{Caso clínico 2.}

Varón de 37 años que consultó al servicio de endocrinología por ginecomastia bilateral, dolorosa, sin secreción, desde hacía 2 años (Figura 4) y en los últimos meses disminución de líbido.

A la exploración se apreció nódulo duro en polo superior de teste izquierdo, bien delimitado de la cabeza del epidídimo y que ecograficamente era hipoecóico, bien delimitado y vascularizado (Figura 5).

La analítica en la que se incluyeron los marcadores testiculares, alfafetoproteina y beta-HCG fueron normales; el estradiol plasmático estaba moderadamente elevado $(54 \mathrm{pg} / \mathrm{ml}$ ) y la testosterona disminuida: $0,8 \mathrm{ng} / \mathrm{ml}$ (valores normales: $2,8-8 \mathrm{ng} / \mathrm{ml}$ ). El espermiograma demostró una oligoastenospermia severa. Se expuso al paciente la posibilidad de efectuar cirugía conservadora ante la convicción clínica de que se tratara de tumor de células de Leydig, pero la rechazó tras conocer el tratamiento quirúrgico mayoritariamente utilizado, prefiririendo que se hiciera cirugía radical. Se practicó orquiectomía inguinal y colocación de prótesis testicular. En la pieza quirúrgica se comprobó que se trataba de una tumoración muy bien capsulada (Figura 6) y de fácil enucleación. Así mismo se realizó un estudio en fresco-frotis apreciándose gran número de cristaloides de Reinke (Figura 7).

El estudio histológico demostró una tumoración testicular bien delimitada, encapsulada, consti-

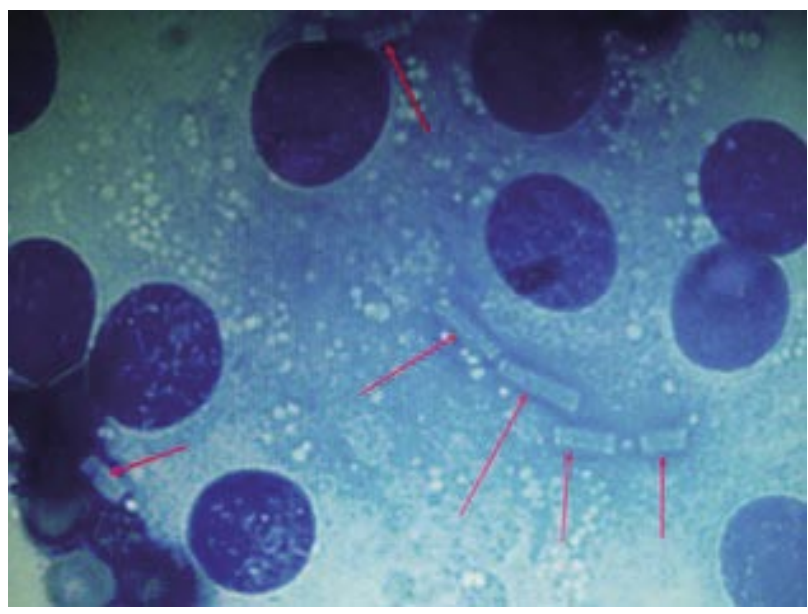

FIGURA 7. Frotis con cristaloides de Reinke (flechas). tuida por células de amplio citoplasma eosinófilo en nidos o sábanas. Estas células mostraban núcleos con leve anisocariosis y nucleolo prominente sin formas atípicas. No se observaron áreas de hemorragia ni necrosis. Las células eran vimentina y calretinina positivas, siendo negativas con AE 1/AE3. Borde quirúrgico libre. En el parénquima testicular no tumoral los túbulos seminíferos muestran leve fibrosis peritubular, aislados grupos atróficos y una difusa detención de la maduración de la serie germinal. El diagnóstico final fue de leydigioma.

A los ocho meses de la intervención había desaparecido el dolor mamario y la ginecomastia se había reducido aproximadamente a la mitad. El estradiol y la testosterona se normalizaron. En el espermiograma de control mejoró el recuento espermático pero no la movilidad.

\section{DISCUSIÓN}

Se estima que alrededor del $10 \%$ y sólo en adultos, los tumores de células de Leydig pueden ser malignos, no existiendo criterios histológicos absolutos para determinar la malignidad y sólo la existencia de metástasis lo confirmaría $(7,8)$. Desde que Kim efectuó su revisión sobre 40 casos (9) y los estudios posteriores de Cheville (10) con 30 y Mc Cluggage (11) con 20, se han propuesto una serie de criterios clínicos e histológicos orientativos de posible malignidad, como son:

- Tumores grandes, por encima de $5 \mathrm{~cm}$.

- Clínica de corta duración.

- Ausencia de manifestaciones endocrinas.

- Mayores de 50 años.

- Displasia celular severa.

- Actividad mitótica superior a 5 por 10 campos de gran aumento.

- Necrosis tumoral

- Márgenes infiltrados.

- Invasión linfática o vascular.

- Aneuploidía del DNA en la citometría de flujo.

-Alto índice de marcador de proliferación celular $\mathrm{MBI}-1$, y alta expresión de proteína p53.

La gran mayoría de TCL se presentan como masa testicular palpable e indolora, o de forma incidental en ecografía, pero hasta en un $30 \%$ por alteraciones endocrinas y tumor oculto.

Estos tumores son hormonoproductores por lo que pueden dar manifestaciones endocrinas, y cuando las dan serán distintas dependiendo de la edad de los pacientes; pueden reproducir un perfil hormonal semejante al de muchas disfunciones 
sexuales endocrinas del adulto e incluso al del carcinoma corticoadrenal, con el inconveniente de que ninguna hormona va a ser secretada en niveles suficientes para que pueda ser útil como marcador tumoral. En los pacientes prepuberales prácticamente la totalidad muestran virilización precoz con desarrollo de caracteres sexuales secundarios: aumento del tamaño de los genitales externos, presencia de vello púbico, cambios de la tonalidad de la voz, etc; sólo en el $10 \%$ de éstos se acompañan de ginecomastia.

Globalmente, los tumores testiculares son responsables del $3 \%$ de casos de ginecomastia (12), pudiendo ser originada por tumores germinales no seminomatosos productores de HCG y en tumores de células de Sertoli y Leydig.

En el adulto el tumor de Leydig provoca manifestaciones endocrinas en el $20-40 \%$ de los casos, en forma de feminización con ginecomastia, disfunción eréctil y disminución de la líbido, oligozoospermia, y atrofia del otro testículo; la ginecomastia puede preceder al diagnóstico del tumor en meses o años como ocurrió en nuestros casos, considerándose su presencia $(9,13,14)$ y un mayor tiempo de evolución de la misma como un factor pronóstico positivo. Los efectos virilizantes del tumor se explican por la excesiva producción de andrógenos, principalmente testosterona y de forma ocasional, androstendiona o deshidroepiandrostendiona; mientras que la ginecomastia está mediada generalmente por estrógenos y se origina como consecuencia de alteraciones en la relación androgenos/estrógenos activos en plasma o en el propio tejido mamario; la feminización aparece al disminuir significativamente dicho cociente, por existir menor producción o actividad de la testosterona, por mayor formación de estrógenos, o por ambas causas. El incremento de estrógenos puede ser producido por el tumor o consecuencia de la aromatización de otros esteroides, pues se conoce que el $75-90 \%$ de los estrógenos provienen de la conversión periférica de androstendiona y testosterona a estrona y estradiol, con $10-25 \%$ de producción de estradiol proveniente de la secreción directa testicular, siendo la célula de Leydig el principal lugar de la síntesis $(3,8,13,15)$.

Se ha tratado de explicar la distinta semiología clínica del adulto y el niño teniendo en cuenta que en el adulto la conversión de testosterona a estradiol se origina por la enzima aromatasa microsomal contenida en las células de Leydig (aumentada en las células tumorales) y en el prepúber esta aromatización se efectúa en las células de Sertoli; de ahí que, la producción estrogénica de las propias células tumorales sea la causante de los hallazgos endocrinos (6). Así en el estudio hormonal del adulto con tumor de Leydig puede haber aumento del estradiol que a su vez bloquea enzimas: 17-hidroxilasa y 17-20 liasa, con lo cual se impide la conversión de progesterona en testosterona. El aumento de estradiol por retroalimentación negativa inhibe la secreción de FSH y LH $(1,2)$, por lo que el patrón hormonal que más frecuente se puede encontrar es: elevación de estradiol, acompañado a veces de disminución de testosterona y gonadotropinas. El patrón más habitual en el estudio hormonal de niños con tumor de células de Leydig revela: elevación de testosterona y 17-cetosteroides, con descenso de las gonadotropinas, lo que obliga al diagnóstico diferencial con la hiperplasia adrenal $(2,6,14)$.

El diagnóstico de la masa en la mayoría de casos se hace por la palpación del tumor a la exploración y se confirma con la ecografía en la que aparece un patrón hipoecóico frecuentemente. En otras ocasiones el diagnóstico se realiza por hallazgo ecográfico al no palparse masas testiculares y en otras la clínica endocrina orientará a la búsqueda de este tipo de tumores. Recientemente en algunos casos se ha utilizado la resonancia magnética (16) en la que se aprecia un marcado realce postcontraste en este tipo de tumores, permitiendo observar mejor la morfología, tamaño, localización y diferenciación con el parénquima sano, signos que orientarán al diagnóstico de fumor de células de Leydig, pudiendo además detectar algún pequeño tumor no visualizado en estudio ecográfico.

El diagnóstico de sospecha de tumor de células de Leydig debe establecerse ante una masa testicular asociada a un cuadro de androgenización o feminizacion con marcadores tumorales negativos (alfa-feto beta-HCG, LDH), siendo en estos casos necesario efectuar estudio hormonal que incluya testosterona, prolactina, estradiol, FSH y LH (17). En nuestro primer caso solo era manifiesta la clínica endocrina no palpándose induraciones testiculares; hasta en el $31 \%$ de los tumores de Leydig no son palpables, siendo este porcentaje menor en otros tipos histológicos (18).

El diagnóstico diferencial debe establecerse con tumores de restos adrenales, hiperplasia de células de Leydig, tumor de células de Sertoli variante calcificante, linfomas y metástasis testiculares, malacoplaquia testicular, plasmocitómas, microlitiasis, quistes dermoides, carcinomas indiferenciados o ginecomastia idiopática $(2,6,17)$.

El estudio histológico suele mostrar células poligonales, núcleo central esférico, pequeño nucleolo y citoplasma granular eosinófilo; en el $20 \%$ existe pigmento lipocrómico citoplasmático, y en el $30 \%$ 
cristales de Reinke $(2,19)$. En 1896, Friedrich Reinke describe estos cristaloides que llevan su nombre, en las células intersticiales del testículo y, aunque no son requisito para el diagnóstico, su presencia es patognomónica del tumor de células de Leydig $(19,20)$. No está clara su significación pero están ausentes en la mayoría de los leydigiomas malignos.

El tratamiento más frecuentemente efectuado es la orquiectomía radical inguinal, como en los tumores testiculares malignos, actitud derivada de la imposibilidad de distinguir de forma inequívoca clínica y preoperatoriamente si se trata de tumor germinal o de células de Leydig, sobre todo cuando el teste contralateral es normal. Se postula la cirugía conservadora por algunos autores en adolescentes y niños y en pacientes con testículo único, pero pudiera ser razonable la cirugía conservadora, con exéresis local, en un grupo de edad más amplio, si se intuye el diagnóstico de tumor de células de Leydig (marcadores normales, clínica endocrina, tumor ecográficamente pequeño, bien delimitado e hipoecóico y por debajo de los 50 años). La justificación vendría dada por el hecho del bajo porcentaje de casos malignos (inexistente en niños y hasta el $10 \%$ en adultos), a la que se sumaría la posible bilateralidad sincrónica o metacrónica hasta un $10 \%$ y porque el acúmulo mayor de casos malignos ocurren por encima de los 50 años.

En los casos que se pretenda hacer cirugía conservadora se efectuará biopsia preoperatoria o intraoperatoria con clampáje del cordón y buscando especialmente los cristales de Reinke (20), pareciendo ser muy útil el estudio citológico de frotis por su rapidez y efectividad para la identificación de localización extracelular (19) de los mismos (en el estudio histológico convencional mediante cortes congelados es mas difícil identificarlos, quizás porque se disuelven durante la fijación y preparación histológica), hallazgo considerado patognomónico de este tumor. En edades prepuberales, con el estudio radiológico y clínico-hormonal, puede efectuarse terapia conservadora, con enucleación del tumor, sin clampáje del cordón ni biopsia previa, e incluso por vía transescrotal (21).

Tras la extirpación tumoral la ginecomastia regresa hasta en el $80 \%$ (15), normalizándose progresivamente el perfil hormonal, pero las alteraciones de la espermatogénesis suelen persistir. La ginecomastia que no ha desaparecido al año de la orquiectomía es tributaria de cirugía plástica.

El seguimiento de estos pacientes, tanto si se efectúa cirugía conservadora como radical, debe ser prolongado aunque el potencial maligno de los mismos es escaso (5-10\%), y se hará durante años pues se han comunicado casos de tumor metacrónico en el teste restante años después de la orquiectomía, aunque en muchos casos con histología similar a la del primero (2), y también algún caso de metástasis a largo plazo. Incluirá de forma periódica estudio hormonal, marcadores tumorales testiculares, TAC abdominopélvico, radiología de torax y ecografía testicular.

En los casos de tumor de células de Leydig maligno el pronóstico es infausto a corto plazo, con una supervivencia media de 2 años desde el diagnóstico. El cáncer metastático de células de Leydig representa el $0,2 \%$ de los canceres testiculares y el $10 \%$ de los leydigiomas. Mas frecuente entre la $5^{\mathrm{a}}$. $6^{a}$ década. La vía de diseminación mas frecuente es a través de las cadenas linfáticas inguinales, iliacas y retroperitoneales $(72 \%)$ y menos frecuente por vía hematógena sobre todo a pulmón, hígado y hueso (7), siendo en general refractario a la radioterapia y quimioterapia convencionales.

En la literatura española existen aproximadamente 90 casos, la mayoría de autores aportan uno o dos casos, solo algunos servicios presentan una casuística con mas pacientes, cinco o más tienen Hita Villaplana (22), Ponce de Leon (15), Pobil (12), Cruceyra (14), y Llerena Ibarguren (23), realizando orquiectomía radical en casi todos los casos con la excepción de unos pocos, en unos por que se trataba de niños y en otros por ser teste único $(2,12,14,15)$. Fernández y cols. (16) presenta tres casos en adultos $y$ tras estudio con RMl en los que se hizo orquiectomía parcial.

\section{BIBLIOGRAFÍA Y LECTURAS RECOMENDADAS (*lectura de interés $y^{* *}$ lectura fundamental)}

1. RADO VELÁSQUEZ, M.A.; DEL VALLE SCHAAN, J.I.; MARTÍN GARCÍA, B. y cols.: "Tumor de células de Leydig. Aportación de dos casos y revisión de la literatura". Actas Urol. Esp., 25: 371, 2001

*2. PEREIRA ARIAS, J.G.; ATECA DIAZ-OBREGON, R.; ULLATE JAIME, V. y cols.: "Tumor testicular de células de Leydig contralateral metacrónico: Tratamiento conservador". Actas Urol. Esp., 25: 133, 2001.

3. CATALA BAUSET, M.; GIRBES BORRAS, J.; CARMENA-RAMON, R. y cols.: "Ginecomastia y tumor de células de Leydig”. An. Med. Intern., 14: 131, 1997. 
4. SACCHI, E.: "Di un caso di gigantismo infantile con un tumore del testicolo". Riv. Sper. Freniat., 21: 149, 1895.

5. CERVOS NAVARRO, J.; TONUTTI, E.; BAYER, J.M.: "Elektromemikroskopiche untersuching eines androgenbildensen Leydig zell tumors endokriologie". Endokrinologie, 47: 23, 1964.

6. HERRERA PUERTO, J.; HERRERA FLORES, C.; PIERNA MANZANO, J. y cols.: "Tumor de células de Leydig. Dos nuevos casos". Actas Urol. Esp., 26: 302, 2002.

*7. JIMÉNEZ LÓPEZ-LUCENDO, N.; FERNÁNDEZ DURÁN, A.; MARTÍN GARCÍA, C. y cols.: "Tumor maligno de células de Leydig. Presentación de un caso y revisión de la literatura”. Arch. Esp. Urol., 52: 174, 1999.

*8. RUBIO TORTOSA, I.; RODRIGO GUANTER, V.; GARCIA TORRELLES, M. y cols.: "Tumor de células de Leydig: Nuestros casos y revisión de la literatura”. Arch. Esp. Urol., 59: 467, 2006.

**9. KIM, I.; YOUNG, R.H.; SCULLY, R.E.: "Leydig cell tumors of the testis. A clinicopathologic study of 40 cases and review of the literature". Am. J. Surg. Pathol., 9: 177, 1985.

**10. CHEVILLE, J.C.; SEBO, T.J.; LAGER, D.J. y cols.: "Leydig cell tumor of the testis. A clinicopathologyc, DNA content, and MIB-1 comparison of nonmetastasizing and metastasizing tumors". Am. J. Surg. Pathol., 22: 1361, 1998.

**11. Mc CLUGGAGE, W.G.; SHANKS, J.H.; ARTHUR, K. y cols.: "Cellular proliferation and nuclear ploidy assessments augment established prognostic factors in predicting malignancy in testicular Leydig cells tumours". Histopathology, 33: 361, 1998.

12. POBIL MORENO, J.L.; MARTINEZ RODRÍGUEZ, J.; MAESTRO DURAN, J.L. y cols.: "Aproximación a la cirugía conservadora del tumor de células de Leydig". Arch. Esp. Urol., 49: 700, 1996.

13. SORIANO GUILLÉN, L.; POZO ROMAN, J.; MUÑOZ CALVO, M.T. y cols.: "Ginecomastia secundaria a tumor de células de Leydig". An. Pediatr., 58: 67, 2003.
*14. CRUCEYRA BETRIU, G.; TEJIDO SANCHEZ, A.; DUARTE OJEDA, J.M. y cols.: "Tumor de células de Leydig: Presentación de ocho casos y revisión de la literatura”. Actas Urol. Esp., 26: 36, 2002.

*15. PONCE DE LEON ROCA, J.; ALGABAARREA, F.; BASSAS ARNAU, L. y cols: "Tumor de células de Leydig del testículo". Arch. Esp. Urol., 53: 453, 2000.

16. FERNANDEZ, G.C.; TARDAGUILA, F.; RIVAS, C. y cols.: "MRI in the diagnosis of testicular Leydig cell tumour". Br. J. Radiol., 77: 521, 2004.

17. CÁNOVAS IVORRA, J.A.; CASTILLO GIMENO, J.M.; MICHELENA BARCENA, J. y cols.: "Tumor de Leydig. A propósito de un nuevo caso y revisión de la literatura". Arch. Esp. Urol., 59: 293, 2006.

18. CARMIGNANI, L.; MORABITO, A.; GADDA, F. y cols.: "Prognostic parameters in adult impalpable ultrasonographic lesions of the testicle". J. Urol., 174: 1035, 2005.

**19. HRIBAR, K.P.; WARNER, N.E.; SHERROD, A.E.: "Cytologic identification of reinke crystalloids in scrapings and imprints of fresh testicular tumors: A simple and rapid technique for intraoperative use". Arch. Pathol. Lab. Med., 129: 65, 2005.

20. REINKE, F.: "Beiträge zur histologie des menschen, I: Ueber krystalloidbildungen in den interstitiellen zellen des menschlichen hodens". Arch. Mikr. Anat., 47: 34, 1896.

21. GERRY HENDERSON, C.; AHMED, A.A.; SESTERHENN, I. y cols.: "Enucleation for prepuberal Leydig cell tumor". J. Urol., 176: 703, 2006.

22. HITA VILLAPLANA, G.; HITA ROSINO, E.; LOPEZ CUBILLANA, P. y cols.: "Tumor de células de Leydig. Comentarios sobre 5 casos". Actas Urol. Esp., 18: 880, 1994.

23. LLARENA IBARGUREN, R.; AZURMENDI SASTRE, V.; PADILLA NIEVA, J. y cols.: "Tumores no germinales del testiculo". Arch. Esp. Urol., 58: 1031, 2005. 